$\xi=2$

\title{
Covid 19 occupational or environmental hazard or both?
}

\author{
Dr. Kiran Kumar N. ${ }^{1}$, Dr. Savitha B Naik ${ }^{2}$, Dr. Laxmi Priya C. H. * ${ }^{3}$, Dr. Pavithra \\ Prabakaran ${ }^{3}$, Dr. Annapoorna B. S. ${ }^{3}$, Dr. Arun Kumar R. V. ${ }^{3}$ \\ ${ }^{1}$ Professor and Head, Department of conservative Dentistry and Endodontics Government dental college \\ and Research institute, Bangalore \\ ${ }^{2}$ Associate professors, Department of conservative Dentistry and Endodontics Government dental college \\ and Research institute, Bangalore \\ ${ }^{3}$ Postgraduate student, Department of conservative Dentistry and Endodontics Government dental college \\ and Research institute, Bangalore \\ *Corresponding author E-mail: priyachitturi1611@gmail.com
}

\begin{abstract}
Covid -19 has taken a huge toll on health care sector. Many health care workers (HCWs) fall susceptible to this pandemic infection leading to occupational health hazard. It also has significantly changed the practice of dentistry. Importance of personal protective equipment cannot be enough stressed upon in present scenario due to uncertainity of vaccine availability and efficacy. Major role in protection of health care workers is played by face masks and respirators. Due to crisis in present scenario, there has been an acute shortage of masks though the production has been upregulated. Also due to increased production of masks, it has posed a significant environmental hazard. This review aims to summarize different types of masks available, their effectiveness and optimization of usage of masks to derive adequate protection thus preventing occupational health hazard with emphasis on eco-friendly masks for a better environmental safety.
\end{abstract}

Keywords: Masks; Respiratory Protective Devices; Biodegradation; Environmental.

\section{Introduction}

COVID 19 pandemic has affected the world globally. It is caused by SARS-coV 2 virus. These Coronaviruses (CoVs) belong to the subfamily Orthocoronavirinae in the family Coronaviridae. There are four genera within the subfamily, namely alpha $(\alpha)$, beta $(\beta)$, gamma $(\gamma)$ and delta $(\delta)$ coronaviruses.[1] The CoV genome exhibit enveloped single-stranded RNA with a size varying between $26-32 \mathrm{kbs}$. Both $\alpha-$ and $\beta-\mathrm{CoV}$ genera are known to infect mammals, whilst $\delta$ - and $\gamma$-CoVs infect birds. Two recent outbreaks of viral pneumonia caused by $\beta$-CoVs are severe acute respiratory syndrome (SARS-coV) and Middle East respiratory syndrome (MERS-coV). [2] In 2002, an outbreak of SARS-coV was first reported in China and then spread quickly worldwide, resulting in hundreds of deaths with an $11 \%$ mortality rate. In 2012, MERS-coV first emerged in Saudi Arabia and subsequently spread to other countries, with a fatality rate of 37\%.[3] In both of these epidemics, the viruses likely originated from bats and then infected humans through other intermediate animal hosts, e.g. the civet (Paguma larvata) for SARS-CoV and the camel for MERS-CoV.[4]

Novel corona virus led to the outbreak of unknown pneumonia that has not been previously reported among humans. The world health organisation named this outbreak as COVID 19. It was declared as "public health emergency of International concern" by world health organisation (WHO) on 30th January 2020. Ever since then all possible measures have been taken to contain the infection. [5]

This novel corona virus spreads majorly by respiratory droplets and partially also through fomite transmission.[6] SARS-CoV 2 can be transmitted through direct or indirect contact with mucous membranes in the eyes, mouth or nose. SARS-CoV 2 spike binds to human angiotensin converting enzyme 2(ACE2) with approximately 10-20-fold higher affinity than the SARS-CoV spike, making it easier to spread from human to human. This particular fact made it a occupational hazard to majority of health care workers (HCWs) who are striving to treat the patients infected by the disease. Because of its mode of transmission, HCWs are at higher risk of acquiring the disease. [7]

Upon entry into alveolar epithelial cells, SARS-CoV-2 replicates rapidly triggering a strong immune response that contributes to cytokine storm syndromes and pulmonary tissue damage. Cytokine storm syndromes are a group of disorders characterised by the uncontrolled production of pro-inflammatory cytokines which can lead to acute respiratory distress syndrome (ARDS) and multiple organ failure.[8] Role of personal protective equipment (PPE) is highlighted in this context to enhance the efficiency of HCWs and at the same time protecting them from this occupational hazard.[9]

There is also a possibility of aerosol transmission in a relatively closed environment with continuous exposure to high concentrations of aerosol. Aerosol generating procedures (AGPs) place HCWs at significant higher risk.[10] Despite utilisation of standard operating protocol including medical masks, gloves, protective gown and eyewear, HCWs have been infected. [11]A study done by papoutsi et al reveals that $>67,569 \mathrm{HCWs}$ are infected by COVID 19. This reconsiders the facts regarding usage of surgical mask in achieving respiratory protection for HCWs ${ }^{[12]}$ Respirators have thus become crucial in preventing the spread of the disease and offering high level of respiratory protection compared to surgical mask. At the same time large scale production and upregulated use of masks has led to significant plastic pollution 
in the environment.[13] This review summarizes various available respirators and the optimization of their usage to achieve high level respiratory protection in $\mathrm{HCW}$ s thereby preventing occupational hazard with emphasis on eco-friendly biodegradable masks.

\section{Limitations of surgical masks}

Conventional face masks do not offer high level respiratory protection to health care workers which is the need of hour in this pandemic. World health organisation (WHO) recommends the use of mask in low risk settings and respirator in high risk settings (aerosol generating procedures) whereas CDC recommends use of respirator in both low risk and high risk settings. Hence there is no consensus regarding the usage of masks. [14] [15]

Face masks are designed to prevent spread of infection from wearer to others. They can protect the wearer from splashes or sprays of blood or body fluids. They have lower filtration efficiency than respirators, also they do not provide a proper seal around the face. These limitations make it crucial to know about various available respirators and newer methods that are in experimental stage to enhance the reuse of respirators to meet the acute scarcity existing during the pandemic. [16]

\section{Respirators}

Respirators are personal protective devices that cover nose and mouth(in some cases, more of the face and head) and operate either by purifying the air inhaled by the wearer through filtering materials or by independently supplying breathable air to the wearer.[17] (figure 1)

Respirators require tight facial seal, necessitating individual fit testing. Initially they were proposed to offer protection from infectious aerosols from patients with tuberculosis. Later, they were recommended for outbreaks and pandemics involving pathogens with potential for aerosol transmission.[18]

Fig. 1: Respirators Can Be Categorised As:

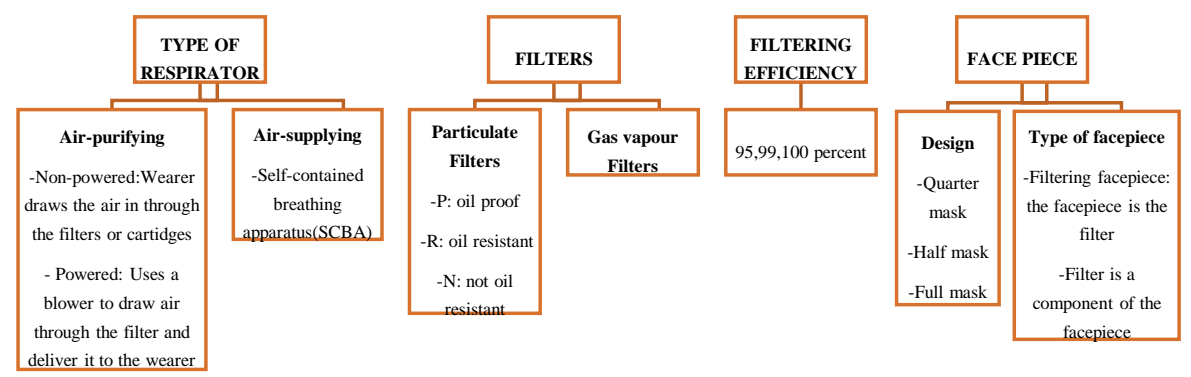

\section{Disposable respirators}

Respirators can be reusable or disposable. National Institute for Occupational Safety and Health (NIOSH) is regulatory body governing the Certification of respirators (42 CFR 84). Most commonly used respirators in health care settings during infectious outbreak are N95filtering face piece respirator (N95FFR). It has 95\% filtration efficiency to a challenge aerosol. (table 1) The structural components of N95 are composed of the outer layer, the filter layer, and the inner layer. The filter layer is a filter fabric generated from nylon, cotton, polyester, and polypropylene. The fiber diameters of the outer layer and filter layer of $\mathrm{N} 95$ are $27.07 \mu \mathrm{m} \pm 3.64 \mu \mathrm{m}$ and $2.79 \mu \mathrm{m} \pm 0.95 \mu \mathrm{m}$, respectively. The diameter of fibers affects its mechanical filtration characteristics. The smaller it is, the higher its mechanical filtration.[19] A structural difference is also found between a disposable surgical mask and a N95 respirator. A disposable surgical mask consists of folded piles of fabrics that are loose-fitting on the user's face, whereas the N95 respirator consists of filtering layers and tight-edge fitting Filtering performance of $\mathrm{N} 95$ also depends on the individual fit as one size doesnot fit all. They can be valve or valveless. Valved respirators are not preferred in health care settings as it doesnot filter the exhaled air predisposing to the spread of the infection.[20] Other N95 mask equivalents are available in the market to meet the excessive demands of pandemic. (table 2)

Table 1: Us, European and Australian Standards and Their Filtration Efficiency

\begin{tabular}{ll}
\hline RESPIRATOR STANDARDS & Table 1: Us, European and Australian Standards and Their Filtration Efficiency \\
\hline FFP1 \& P1 & $80 \%$ \\
FFP2 \& P2 & $94 \%$ \\
N 95 & $95 \%$ \\
N 99 \& FFP3 & $99 \%$ \\
P3 & $99.95 \%$ \\
N100 & $99.97 \%$ \\
\hline
\end{tabular}


Table 2: National Institute for Occupational Respirators: Safety and Health's (NIOSH's) Approved List of Comparable Respirator

\begin{tabular}{ll}
\hline Country & Acceptable product classifications \\
\hline \multirow{2}{*}{ Australia } & P3 \\
Brazil & P2 \\
& PFF3 \\
China & PFF2 \\
& KN 100, KP100 \\
Europe & KN95,KP95 \\
& FFP3 \\
Japan & FFP2 \\
Korea & DS/DL3 \\
& DS/DL2 \\
Mexico & Special 1 \\
& N100,P100,R100 \\
& N99,P99,R99 \\
US NIOSH & N95,P95,R95 \\
& N100,P100,R100 \\
& N99,P99,R99 \\
\hline
\end{tabular}

\section{Reusable elastomeric respirators}

Reusable respirators are made of elastomeric materials which can withstand high elastic deformation without rupture. They can be half face or full face respirators (figure 1). They can be cleaned, disinfected and reused. They are NIOSH approved and provide equivalent protection to N95FFRs. Major limitation is that they require maintenance of replaceable components like inhalation and exhalation valves, straps, filters and canisters. Also, there is lack of consensus regarding disinfection of these reusable respirators. [21]

\section{Powdered air purifying respirators (PAPR)}

They are air purifying respirators equipped with powered blower and filters which can be interchangeable and disposable (figure 2). Filters mainly comprised of high efficiency particulate air filters (HEPA). They can be loose fitting or tight fitting. Loose fitting PAPR are preferred in health care settings. PAPR offers greater respiratory protection than conventional N95FFR.[22]

Despite higher level of respiratory protection offered, donning and doffing of this device is cumbersome. Also it can have ergonomic impact from the weight and noise of the device. They pose difficulties in communication and also they are expensive than reusable respirators. These limits its widespread usage compared to N95FFR restricting its use to high risk situations. [23]
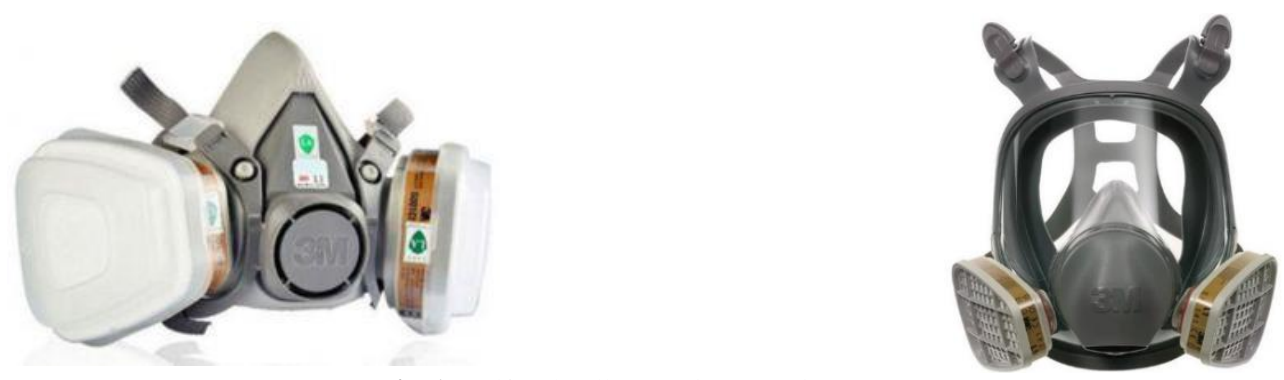

Fig. 1: Half and Full-Face Piece Respirators.

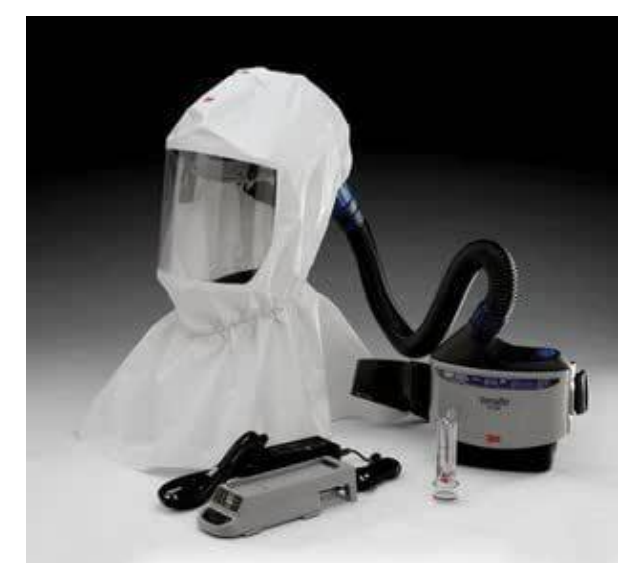

Fig. 2: Powered Air Purifying Respirators (Paprs).

\section{Mode of optimisation of usage of N95 masks}

CDC has proposed the concept of extended use and limited reuse to overcome the existing shortage of supply of N95 masks. Extended use refers to the practice of wearing the same N95 respirator for multiple patients without removing it in between. Face shield can be utilised to minimise the soiling of the mask. 
Limited reuse includes usage of same mask for multiple encounters with patients but doffing after each encounter. Though it is reuse, it is limited for few encounters up to 5 times. These strategies of extended use and limited reuse can be used for conserving respirators during the pandemic crisis.[24]

\section{Masks - A environmental hazard}

Disposable face masks are made up of polymers such as polypropylene, polyurethane, polyacrylonitrile, polystyrene, polycarbonate, polyethylene, or polyester which are non-biodegradable. Thus they are not ecofriendly.[25] They consist of three layers; an inner hydrophilic layer of soft fibres, middle layer of melt-blown filter, and an outer hydrophobic layer of nonwoven fibers. The melt-blown filter is the main filtering layer of the mask produced by the conventional fabrication of micro- and nanofibers.[26]

According to the WHO estimates, approximately 89 million medical masks were needed to respond to Covid-19 each month (WHO, 2020). This demand has resulted in an unprecedented rise in the global production of face masks which are produced using polymeric materials. ${ }^{27}$ Increased production and usage of masks in this pandemic crisis has posed an new environmental challenge. It largely generates the plastic waste in the environment which may pose risk of environmental litter in both terrestrial as well as aquatic ecosystems. This global pandemic has been indirectly leading to increased environmental pollution disrupting the harmony of ecosystems.[28]

Plastics first break down into microplastics and eventually into even smaller nanoplastics. These tiny fibres are long-lived polymers that can accumulate in food chains. Just one mask can produce millions of particles, each with the potential to also carry chemicals and bacteria up the food chain and potentially even into humans raising a concern on global food safety. The presence of plastics in the environment has also been reported as contributing significantly to climate change due to carbon emission.[29]

UCL (university college London) Plastic Waste Innovation report carried out an LCA (life cycle assessment) on UK-wide face maskadoption scenarios including single use mask/day, reusable mask with no filter with manual or machine wash, reusable masks without filters with manual or machine wash. This study showed that the use of reusable masks significantly reduces the amount of waste by $95 \%$, followed by reusable masks with disposable filters $(60 \%)$. Reusable masks without filter had the general lowest contribution to climate change ( $<2.00 \mathrm{E}+008 \mathrm{Kg} \mathrm{CO} 2 \mathrm{eq})$, when considering manufacturing, transport, and use. Conversely, single use masks and reusable masks with disposable filters had the highest contribution to climate change $(\sim 1.47 \mathrm{E}+009$ and $1.50 \mathrm{E}+009$; respectively Kg CO2 eq). Thus, the use of single use masks would aggravate climate change by 10 times than using reusable masks.[30]

Also littered face masks in the environment can act as mode of disease transmission as it has been reported that SARS-coV 2 can stay upto 5 days over mask (figure 3). To overcome this challenge, various novel approaches of environment friendly biodegradable masks have been tried upon.[31]

Biodegradable masks reduce the risk of environmental pollution thereby rendering it plastic free. Various materials has been proposed to create a filter similar to melt blown layer of N95 mask. Thus it makes material more eco friendly and at the same time incorporating the efficiency required to afford respiratory protection[32].

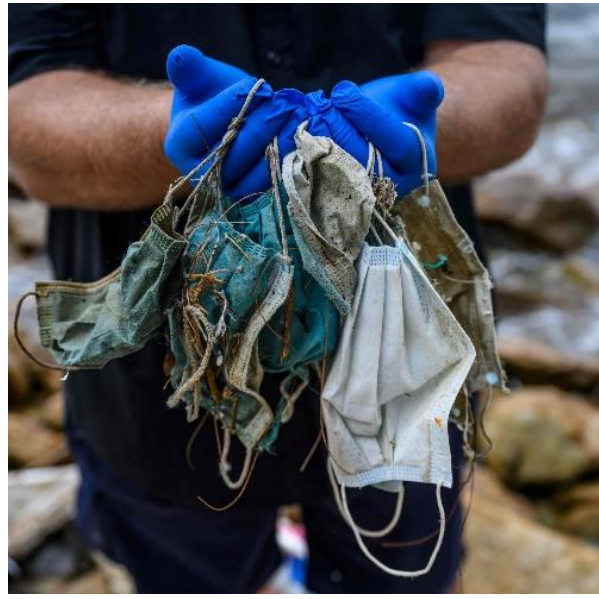

Fig. 3: Masks Environmental Hazard.

\section{Novel strategies to overcome plastic pollution - Biodegradable masks}

Many natural and biodegradable polymers can be obtained from fishery by-products, such as chitin and its derived compounds, from plant biomass such as alginates, cellulose, and polyphenolic lignin, or from bacteria fermentation such as polyhydroxyalkanoates(PHA), PLA(polylactic acid), chitin nanofibrils, nanolignin and pullulan . By utilising these polymers, it will be possible to create biodegradable non-woven structures with biological functions, useful to produce biodegradable surgical masks.[33]

Surgical masks may be fabricated from these natural polymers by the assembly of four or more biodegradable layers, alternating hydrophobic and hydrophilic layers with films able to avoid the passage of microorganisms and viruses. They have to be specifically designed for providing the right mechanical properties, for being easily workable by electro-spinning, melt spinning, and wet spinning, for having agreeable shelf life and degradation time, thus resulting in biocompatible masks which are eco-friendly. [34]

\section{Eco-friendly innovations}

a) AirX mask

A Vietnamese Company, ShoeX, created the world's first biodegradable face mask, AirX. AirX face masks offer $99.99 \%$ dual antibacterial technology with two layers of protection. The first layer is woven from coffee yarn using PowerKnit technology and provides a comfortable fit for sensitive skin. The mask has a biodegradable filter inside developed by silver nanotechnology and coffee. It is washable and reusable. Its filter does not need to be washed and lasts for 30 days. The mask has a natural coffee aroma and offers UV Ray protection (figure 4). 
AirX has obtained the AATCC 100 certification, the textile industry's standard for antimicrobial fabric performance in the USA. It is available commercially in several designs and colours.This product is a more sustainable alternative to medical-grade masks. [35]

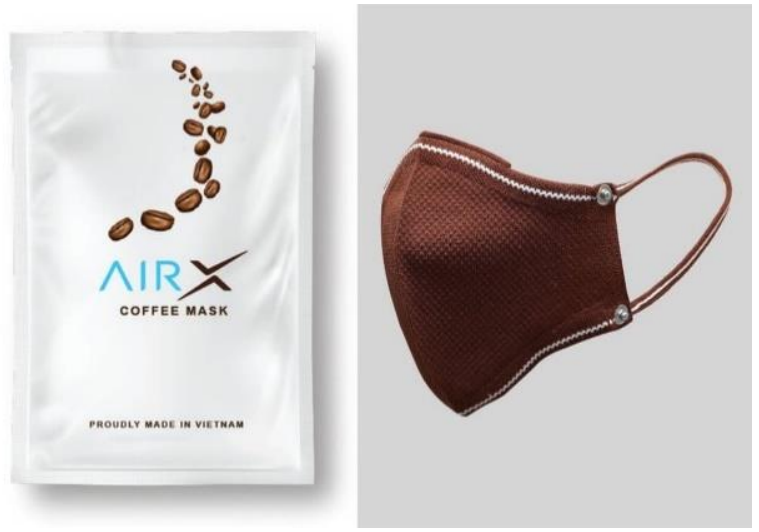

Fig. 4: AirX Mask.

b) Neem, Turmeric \& Basil Biodegradable 'Pavitrapati' Mask

The Indian Defence Institute of Advanced Technology (DIAT) has developed a cotton mask using a herbal extract, and claimed that it acts as "virus-neutraliser and resists pathogens effectively". A herbal extract obtained from neem oil, turmeric, holy basil, carom seeds, black pepper, gum arabic, clove, sandalwood and saffron has been used in the non-woven nano-fibre of this three-layered biodegradable mask, named "pavitrapati", a patented invention (figure 5)

The product is antibacterial, anti-fungal, antiviral, porous, super-hydrophobic (outer layer of mask), hydrophilic (inner layer) and biodegradable and might be able to fight against COVID-19. Masks samples were tested for air permeability/ breathability, nano-fibre mat porosity, biodegradability and mechanical properties as per the American Society for Testing and Materials standards.

The 'pavitrapati' mask is cotton-based, bio-degradable and can be reused up to three washing cycles. The material can be used for PPE (garment, gloves, gown, face protection and head cover). [36] [37].

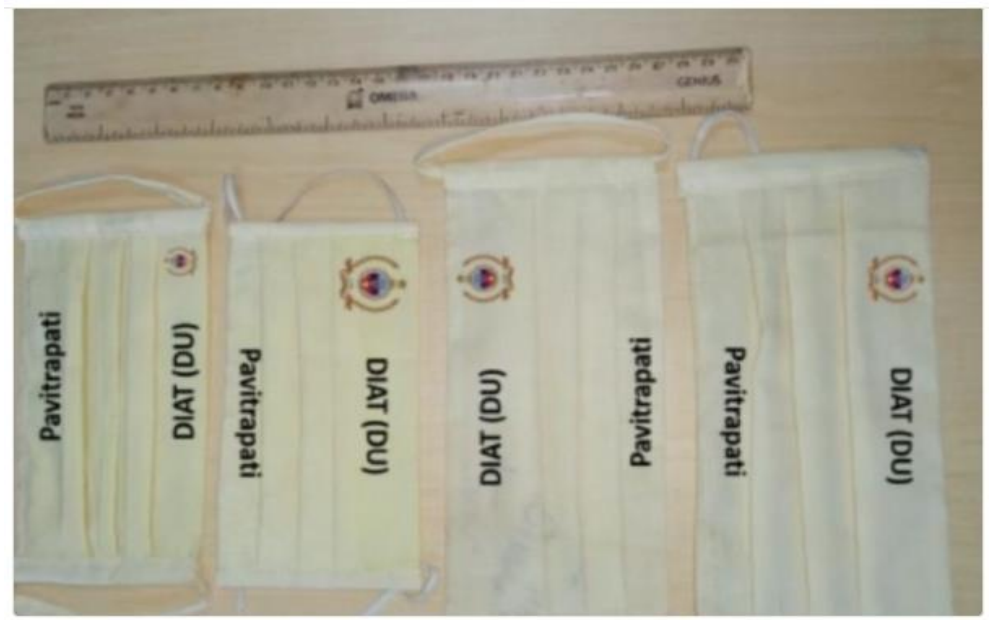

Fig. 5: Pavitrapati Mask.

c) Compostable and Biodegradable N95 Masks - "Can-Mask"

Canada's University of British Columbia BioProducts Institute has designed a green version of the medical grade N95 face masks to supply chain shortage of masks amidst pandemic. It is called can-mask or Canadian mask (figure 6). It can be composted and is biodegradable. The Canadian-Mask or Can-Mask frame uses locally available wood fibre from a variety of softwoods including pine, spruce and cedar and even recycled paper. Two prototypes have been developed. One with the commercial N95 filter in front and another with a woodbased special filter.[38] [39].

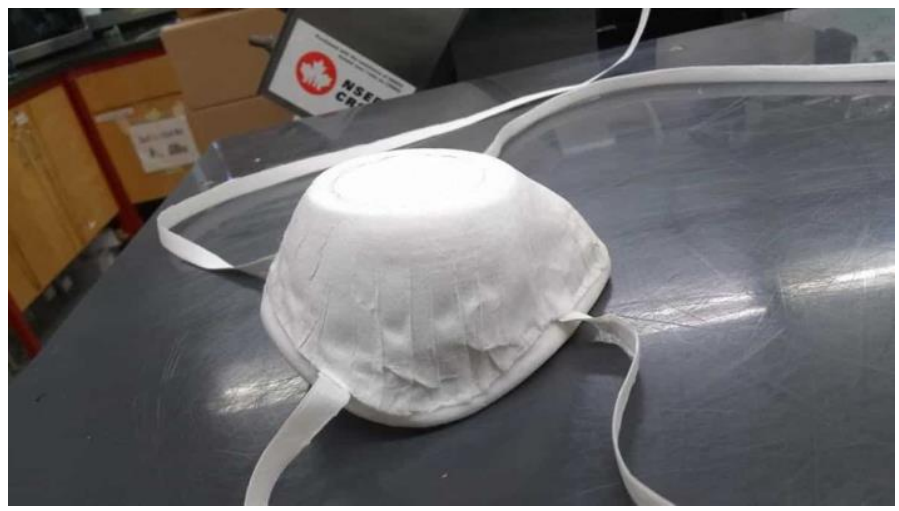

Fig. 6: Can or Canadian Mask. 
d) Abaca face masks

Philippines-based handmade product company came up with a solution to stop plastic pollution by introducing medical-grade, single-use face masks made from a biodegradable material called abaca leaf fibers (figure 7). The plant is like the banana tree and is as durable as polyester but will decompose within two months. These masks meet all the safety requirements, stop aerosols and saliva droplets, and can be washed and reused. The abaca face masks are hypoallergenic, have lower water absorption, and according to the Department of Science and Technology (DOST), "abaca is seven times better in terms of filtration and protection than the ordinary cloth mask." [40][41].

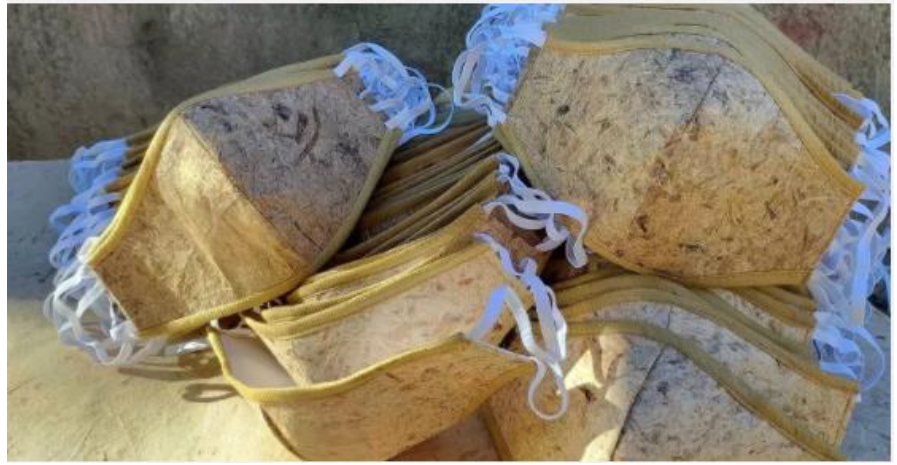

Fig. 7: Abaca Masks.

e) Geochanvre masks

Geochanvre is a french industrial company using sustainable development with zero-waste industrialized production of natural, biodegradable, and biocompostable geotextiles for planting, and packaging. Followind COVID-19 pandemic , the company proposed that their compostable material could be used to fabricate filters for masks. They stated that they have created the first ecological and ethical consumer mask. designed and produced in france. The mask is biocompostable, composed of a $100 \%$ vegetable filtering felt in natural french hemp fibers, with performance controlled by the DGA (French Directorate General of Armaments and sold as ready-to-use or as a kit depending on your needs (figure 8 ).

Advantages of the geochanvre mask include $89 \%$ filtration efficiency level at $3 \mu \mathrm{m}$ particles, air permeability of 459 liters / m2 / sec for depression of $100 \mathrm{~Pa}$, and a natural, local compostable product. The single-use mask features filtering felt hemp without glue, additives or treatment, lined with a dark protective veil in compostable cornstarch. The elastic band used to fix the mask on your face is also recyclable. [42] [43].

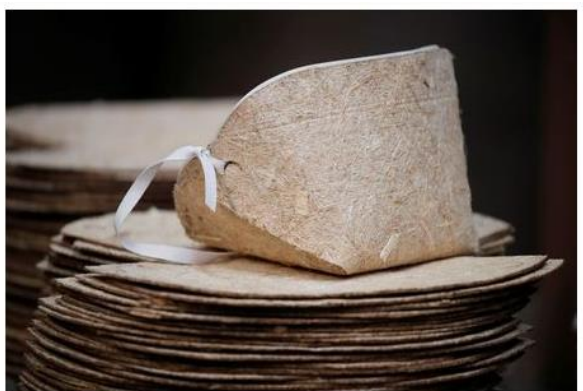

Fig. 8: Geochanvre Masks.

f) Hello masks / See-Through Transparent Masks

Scientists at EMPA (Swiss Federal Laboratories for Materials Science and Technology) and EPFL's Essential Tech Center have developed a fully transparent surgical mask called as "HelloMask"(figure 9) . A start-up HMCARE is marketing the mask and producing on an industrial scale. Masks have proven problem for those in the deaf community as the face coverings make speech reading difficult, but a clear mask could be a solution. The startup has come up with the HelloMask, a transparent surgical mask with the intention to let health care workers communicate with patients in a more natural way. This isn't the first transparent mask out there but the regular transparent ones have a plastic window that can fog up and is not breathable.[44]

The researchers focused on finding a material that was either recyclable and biodegradable. These masks are made at $99 \%$ from a biomass derivative to make them eco-friendly. Using a technique called "electrospinning", an electrical force is used to create ultra-thin polymer fibres with pore size of $100 \mathrm{~nm}$, which are then used to fabricate their masks. [45]

Plastic used to achieve transparency isn't porous, making it hard for the wearer to breathe and it can fog up easily. The Empa and EPFL researchers spent two years finding the right combination of transparency, resistance and porosity. They eventually came up with a membrane made from a polymer developed specifically for this application. They have produced fine electrospun membranes with a pore size of about 100 nanometers. The architecture of the fibers creates extremely small gaps that allow air to pass through but hold back viruses and bacteria. [46]. 


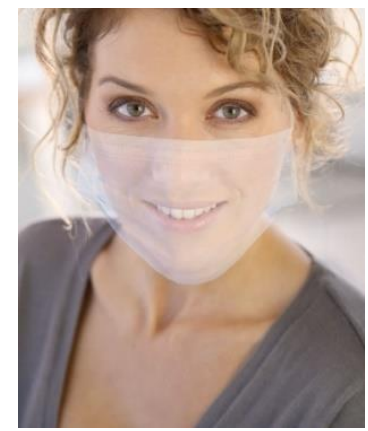

Fig. 9: Hello Masks.

\section{Conclusions}

COVID-19 pandemic has created a upheaval in terms of health, finance and economic status globally. There is upregulation of production of single use and disposable masks to control the spread of the disease, resulting in plastic pollution. This has potentially proved disastrous to the ecosystem. Emphasis should thus be given on mask reuse, reusable respirators and biodegradable masks to overcome the problem. Mask reuse and reusable respirators are in practise to cope up with shortage of supply of the masks owing to its increase usage and stock piling. However, despite better protection ability, it is difficult to wear these respirators for prolonged periods which is the shortcoming of respirators.

Recent studies have placed an emphasis on the invention of biodegradable masks to overcome the plastic hazard, to increase reuse potential and to provide better breathing compatibility over respirators. Moreover, plastic pollution caused by the nonbiodegradable masks can affect the terrestrial and aquatic ecosystems. They can further cause the cross infection owing to the fact that COVID 19 virus can survive up to 5 days or more on outer layer of these masks. This necessitates the improvements in the material aspect of masks to make them ecofriendly . Many innovative biodegradable mask like compostable Can or Canadian mask, neem, turmeric and basil based pavitrapati mask are under trials and patented. They come with significant advantage of filtering capacity and biodegradability. Thus these eco-friendly masks can be a future to keep a check on plastic hazard caused by upregulated use of single use and disposable masks.

Eco-friendly face masks are recommended for the environment, but at the same time these face masks should be three-layered and successfully designed to stop the airborne droplets and aerosols. Only if these standards are met, it can be recommended for use. However, extent of their filtering capacity in comparison with conventional NIOSH approved N95 respirator is still unknown. With improvements in design and filtering ability, biodegradable masks can surely be a game changer in this COVID 19 pandemic crisis.

\section{References}

[1] Li H, Liu SM, Yu XH, Tang SL, Tang CK. Coronavirus disease 2019 (COVID-19): current status and future perspectives. Int J Antimicrob Agents. 2020;55(5):105951. https://doi.org/10.1016/j.ijantimicag.2020.105951.

[2] Pal M, Berhanu G, Desalegn C, Kandi V. Severe Acute Respiratory Syndrome Coronavirus-2 (SARS-CoV-2): An Update. Cureus. 2020;12(3):e7423. https://doi.org/10.7759/cureus.7423.

[3] Raoult D, Zumla A, Locatelli F, Ippolito G, Kroemer G. Coronavirus infections: Epidemiological, clinical and immunological features and hypotheses. Cell Stress. 2020;4(4):66-75. Published 2020 Mar 2. https://doi.org/10.15698/cst2020.04.216.

[4] Yuan S, Jiang SC, Li ZL. Analysis of Possible Intermediate Hosts of the New Coronavirus SARS-CoV-2. Front Vet Sci. 2020;7:379. https://doi.org/10.3389/fvets.2020.00379.

[5] Sohrabi C, Alsafi Z, O'Neill N, et al. World Health Organization declares global emergency: A review of the 2019 novel coronavirus (COVID-19) [published correction appears in Int J Surg. 2020 May;77:217]. Int J Surg. 2020; 76:71-76. https://doi.org/10.1016/j.ijsu.2020.02.034.

[6] Jayaweera M, Perera H, Gunawardana B, Manatunge J. Transmission of COVID-19 virus by droplets and aerosols: A critical review on the unresolved dichotomy. Environ Res. 2020; 188:109819. https://doi.org/10.1016/j.envres.2020.109819.

[7] Zheng J. SARS-CoV-2: an Emerging Coronavirus that Causes a Global Threat. Int J Biol Sci. 2020;16(10):1678-1685. Published 2020 Mar 15. https://doi.org/10.7150/ijbs.45053.

[8] Costela-Ruiz VJ, Illescas-Montes R, Puerta-Puerta JM, Ruiz C, Melguizo-Rodríguez L. SARS-CoV-2 infection: The role of cytokines in COVID-19 disease. Cytokine Growth Factor Rev. 2020; 54:62-75. https://doi.org/10.1016/j.cytogfr.2020.06.001.

[9] Park SH. Personal Protective Equipment for Healthcare Workers during the COVID-19 Pandemic. Infect Chemother. 2020;52(2):165-182. https://doi.org/10.3947/ic.2020.52.2.165.

[10] Harding H, Broom A, Broom J. Aerosol-generating procedures and infective risk to healthcare workers from SARS-CoV-2: the limits of the evidence. J Hosp Infect. 2020;105(4):717-725. https://doi.org/10.1016/j.jhin.2020.05.037.

[11] Baker TL, Greiner JV, Maxwell-Schmidt E, Lamothe PH, Vesonder M. Guidelines for Frontline Health Care Staff Safety for COVID-19. J Prim Care Community Health. 2020;11:2150132720938046. https://doi.org/10.1177/2150132720938046.

[12] Papoutsi E, Giannakoulis VG, Ntella V, Pappa S, Katsaounou P. Global burden of COVID-19 pandemic on healthcare workers. ERJ Open Res. 2020;6(2):00195-2020. https://doi.org/10.1183/23120541.00195-2020.

[13] Wang J, Pan L, Tang S, Ji JS, Shi X. Mask use during COVID-19: A risk adjusted strategy. Environ Pollut. 2020;266(Pt 1):115099. https://doi.org/10.1016/j.envpol.2020.115099.

[14] MacIntyre CR, Chughtai AA, Rahman B, et al. The efficacy of medical masks and respirators against respiratory infection in healthcare workers. Influenza Other Respir Viruses. 2017;11(6):511-517. https://doi.org/10.1111/irv.12474.

[15] Chughtai AA, Seale H, MacIntyre CR. Availability, consistency and evidence-base of policies and guidelines on the use of mask and respirator to protect hospital health care workers: a global analysis. BMC Res Notes. 2013;6:216. https://doi.org/10.1186/1756-0500-6-216.

[16] Institute of Medicine (US) Committee on Personal Protective Equipment for Healthcare Personnel to Prevent Transmission of Pandemic Influenza and Other Viral Respiratory Infections: Current Research Issues; Larson EL, Liverman CT, editors. Preventing Transmission of Pandemic Influenza and Other Viral Respiratory Diseases: Personal Protective Equipment for Healthcare Personnel: Update 2010. Washington (DC): National Academies Press (US); 2011. 3, Designing and Engineering Effective PPE. Available from: https://www.ncbi.nlm.nih.gov/books/NBK209586/

[17] Andersen BM. Protection of Upper Respiratory Tract, Mouth and Eyes. Prevention and Control of Infections in Hospitals. 2018;129-146. https://doi.org/10.1007/978-3-319-99921-0 13.

[18] Danyluk Q, Hon CY, Neudorf M, Yassi A, Bryce E, Janssen B, Astrakianakis G. Health care workers and respiratory protection: is the user seal check a surrogate for respirator fit-testing? J Occup Environ Hyg. 2011;8(5):267-70. https://doi.org/10.1080/15459624.2011.566016.

[19] NIOSH Guide to the Selection and Use of Particulate Respirators. Available from https://www.cdc.gov/niosh/docs/96-101/default.html 
[20] Roberge RJ. Effect of surgical masks worn concurrently over N95 filtering facepiece respirators: extended service life versus increased user burden J Public Health Manag Pract. 2008;14(2): E19-26. https://doi.org/10.1097/01.PHH.0000311904.41691.fd.

[21] National Academies of Sciences, Engineering, and Medicine; Health and Medicine Division; Board on Health Sciences Policy; Committee on the Use of Elastomeric Respirators in Health Care; Liverman CT, Yost OC, Rogers BME, et al., editors. Reusable Elastomeric Respirators in Health Care: Considerations for Routine and Surge Use. Washington (DC): National Academies Press (US); 2018 Dec 6. 2, Elastomeric Respirators. Available from: https://www.ncbi.nlm.nih.gov/books/NBK540078/

[22] Board on Health Sciences Policy; Institute of Medicine. The Use and Effectiveness of Powered Air Purifying Respirators in Health Care: Workshop Summary. Washington (DC): National Academies Press (US); 2015 May 7. 2, Defining PAPRs and Current Standards. Available from: https://www.ncbi.nlm.nih.gov/books/NBK294223/

[23] Roberts V. To PAPR or not to PAPR?. Can J Respir Ther. 2014;50(3):87-90.

[24] Implementing Filtering Facepiece Respirator (FFR) Reuse, Including Reuse after Decontamination, When There Are Known Shortages of N95 Respirators. Available from https://www.cdc.gov/coronavirus/2019-ncov/hcp/ppe-strategy/decontamination-reuse-respirators.html

[25] Aragaw TA. Surgical face masks as a potential source for microplastic pollution in the COVID-19 scenario. Mar Pollut Bull. $2020 ; 159: 111517$. https://doi.org/10.1016/j.marpolbul.2020.111517.

[26] Chua MH, Cheng W, Goh SS, Kong J, Li B, Lim JYC et al. Face Masks in the New COVID-19 Normal: Materials, Testing, and Perspectives. Research (Wash D C). 2020:7286735. https://doi.org/10.34133/2020/7286735.

[27] Shortage of personal protective equipment endangering health workers worldwide.Available from https://www.who.int/news/item/03-03-2020-shortage-of-personal-protective-equipment-endangering-health-workers-worldwide

[28] Coronavirus face masks: an environmental disaster that might last generations. Available from https://theconversation.com/coronavirus-face-masksan environmental-disaster-that-might-last-generations-144328

[29] Fadare OO, Okoffo ED. Covid-19 face masks: A potential source of microplastic fibers in the environment. Sci Total Environ. 2020;737:140279. https://doi.org/10.1016/j.scitotenv.2020.140279.

[30] The environmental dangers of employing single-use face masks. Available from https://www.ucl.ac.uk/covid-19-research/snippets/2020/jun/environmental-dangers-employing-single-use-face-masks

[31] Sim SW, Moey KS, Tan NC. The use of facemasks to prevent respiratory infection: a literature review in the context of the Health Belief Model. Singapore Med J. 2014;55(3):160-167. https://doi.org/10.11622/smedj.2014037.

[32] Karim N, Afroj S, Lloyd K, Oaten LC, Andreeva DV, Carr C, et al. . Sustainable personal protective clothing for healthcare applications: a review. ACS Nano. (2020) 14:12313-40. https://doi.org/10.1021/acsnano.0c05537.

[33] Babu RP, O'Connor K, Seeram R. Current progress on bio-based polymers and their future trends. Prog Biomater. 2013;2(1):8. https://doi.org/10.1186/2194-0517-2-8.

[34] Post-COVID-19: An Opportunity to Produce Biodegradable Goods \& Surgical Masks to Save the Environment. Available from https://www.researchgate.net/publication/344649622_Post-COVID-19_An_Opportunity_to_Produce_Biodegradable_Goods_Surgical_Masks_to_Save_the_Environment

[35] World's first face mask made from coffee - an eco-friendly message from AirX. Available from https://www.prnewswire.com/news-releases/worldsfirst-face-mask-made-from-coffee--an-eco-friendly-message-from-airx-301044250.html

[36] "Launching of "Pavitrapati" Ayurvedic Biodegradable Face Mask and Anti-Microbial Body Suit Named "Aushada Tara". Available from https://pib.gov.in/PressReleaseIframePage.aspx?PRID=1645554

[37] This biodegradable mask resists pathogens, and has the goodness of neem, turmeric \& basil. https://cssm.etimg.com/magazines/panache/this-biodegradablemask-resists-pathogens-and-has-the-goodness-of-neem-turmeric-basil/articleshow/76383623.cms

[38] UBC researchers develop biodegradable medical masks made from wood fibre. Available from https://www.cbc.ca/news/canada/british-columbia/biodegradable-medical-masks-1.5579092

[39] Canadian researchers develop biodegradable face mask. Available from https://www.theengineer.co.uk/canadian-biodegradable-face-mask/

[40] Masks made from banana-tree species cut plastic waste from covid-19. Available from https://makerfairerome.eu/en/masks-made-from-banana-treespecies-cut-plastic-waste-from-covid-19/

[41] Can eco-friendly masks help stop marine pollution? Available from https://timesofindia.indiatimes.com/life-style/spotlight/can-ecofriendly-masks-help-stop-marine-pollution/articleshow/78177057.cms

[42] From field to compost: French firm develops hemp face masks By Reuters Staff. Available from https://www.geochanvre.fr/from-field-to-compostfrench-firm-develops-hemp-face-masks-by-reuters-staff/

[43] The geochanvre mask is a bio-compostable mask in natural hemp fibers. Available from https://www.designboom.com/design/geochanvre-maskbiocompostable-hemp-fibers-08-20-20/

[44] First transparent surgical mask goes into production. Available from https://www.empa.ch/web/s604/hello-mask-hmcare

[45] Transparent Surgical Mask Made from Biomass-Based Material. Available from https://www.medicaldesignbriefs.com/component/content/arti$\mathrm{cle} / \mathrm{mdb} / \mathrm{stories} / \mathrm{blog} / 37152$

[46] Swiss develop first see-through surgical mask. Available from https://www.swissinfo.ch/eng/swiss-develop-first-see-through-mask/45824518

[47] Wang J, Pan L, Tang S, Ji JS, Shi X. Mask use during COVID-19: A risk adjusted strategy. Environ Pollut. 2020 Nov;266(Pt 1):115099. https://doi.org/10.1016/j.envpol.2020.115099. 